\title{
Lateral lymph node dissection reduces local recurrence of locally advanced lower rectal cancer in the absence of preoperative neoadjuvant chemoradiotherapy: a systematic review and meta-analysis
}

\author{
Xiang Gao ${ }^{1,2+}\left(\mathbb{D}\right.$, Cun Wang ${ }^{1,2 \dagger}$, Yongyang Yu ${ }^{1,2+}$, Dujanand Singh ${ }^{1,2}$, Lie Yang ${ }^{1,2^{*}}$ and Zongguang Zhou ${ }^{1,2^{*}}$
}

\begin{abstract}
Background: The impact of lateral lymph node dissection (LLND) in locally advanced lower rectal cancer remains controversial. This study is to compare total mesorectal excision (TME) with or without LLND in lower rectal cancer cases of stage $\| / I I I$.

Methods: The electronic databases were systematically searched that compared TME with or without LLND among patients with lower rectal cancer in clinical stage II/III. Subgroup analysis was performed considering neoadjuvant chemoradiotherapy (nCRT). The hazard ratios (HR), relative risk (RR), and weighted mean difference (WMD) were pooled.

Results: Twelve studies of 4458 patients of this meta-analysis demonstrate, LLND alone significantly reduced the local recurrence rate of patients who did not receive $\mathrm{nCRT}$ (RR 0.71, $P=0.004$ ), while the difference was not significant when combined with $\mathrm{nCRT}$ (RR 0.70, $P=0.36$ ). The analysis shows TME with LLND was associated with significantly longer operation time (WMD $90.73 \mathrm{~min}, P<0.001)$, more intraoperative blood loss (WMD $303.20 \mathrm{~mL}, P$ $<0.001$ ), and postoperative complications ( $R R=1.35, P=0.02$ ). Whereas urinary dysfunction (RR $1.44, P=0.38)$, sexual dysfunction (RR 1.41, $P=0.17$ ), and postoperative mortality ( $R R=1.52, P=0.70$ ), were similar between these two groups. Statistically, no significant differences were observed in OS (HR 0.93, $P=0.62$ ), DFS (HR 0.99, $P=0.96$ ), total recurrence (RR 0.98, $P=0.83$ ), lateral recurrence (RR 0.49, $P=0.14$ ), or distal recurrence (RR $0.95, P=0.78$ ) between these two groups regardless of whether nCRT was performed or not.

Conclusions: The study shows LLND alone decreases the local recurrence without using nCRT irrespective of the survival advantage in locally advanced lower rectal cancer. The benefit of controlling local recurrence by LLND alone makes us reconsider the usage of nCRT with LLND.

(Continued on next page)
\end{abstract}

\footnotetext{
*Correspondence: lie_222@163.com; zhou767@163.com

${ }^{+}$Xiang Gao, Cun Wang and Yongyang Yu contributed equally to this work. ${ }^{1}$ Institute of Digestive Surgery, Sichuan University, Chengdu, Sichuan, China Full list of author information is available at the end of the article
}

(c) The Author(s). 2020 Open Access This article is licensed under a Creative Commons Attribution 4.0 International License, which permits use, sharing, adaptation, distribution and reproduction in any medium or format, as long as you give appropriate credit to the original author(s) and the source, provide a link to the Creative Commons licence, and indicate if changes were made. The images or other third party material in this article are included in the article's Creative Commons licence, unless indicated otherwise in a credit line to the material. If material is not included in the article's Creative Commons licence and your intended use is not permitted by statutory regulation or exceeds the permitted use, you will need to obtain permission directly from the copyright holder. To view a copy of this licence, visit http://creativecommons.org/licenses/by/4.0/. The Creative Commons Public Domain Dedication waiver (http://creativecommons.org/publicdomain/zero/1.0/) applies to the data made available in this article, unless otherwise stated in a credit line to the data. 
(Continued from previous page)

Trial registration: The protocol for this meta-analysis was registered prospectively with PROSPERO (CRD420201355 75) on 16 May 2019.

Keywords: Rectal cancer, Lateral lymph node dissection, Total mesorectal excision, Neoadjuvant chemoradiotherapy

\section{Background}

The total mesorectal excision (TME) technique has significantly improved the pathological and oncological outcomes and has become the standard surgical procedure for rectal cancer. Approximately $14-30 \%$ of patients with lower rectal cancer in clinical stage II/III develop pelvic lateral lymph node (LLNs) metastases, which is beyond the surgical field of TME and is associated with an increased incidence of local recurrence and decreased survival [1, 2]. In Japan, lateral lymph node dissection (LLND) has been recommended as the standard treatment for patients with lower rectal cancer in clinical stage II/III since the 1970s [3, 4]. On the other hand, Western surgeons believe, LLNs metastases were a sign of distant metastasis and cannot be eliminated by surgery. Therefore, preoperative nCRT instead of LLND has become the standard regimen for the treatment of locally advanced lower rectal cancer in Western countries $[5,6]$. However, studies have shown that preoperative nCRT could not completely eradicate the metastatic LLNs, suggesting nCRT followed by TME and LLND may be more effective in the management of locally advanced lower rectal cancer $[7,8]$.

The efficiency and safety of LLND in locally advanced lower rectal cancer remain controversial in studies. Some studies have revealed LLND could considerably reduce the local recurrence of patients with rectal cancer and improve survival [9, 10]. Where other studies showed LLND has no benefits in improving survival or reducing recurrence rates. Additionally, it increases urinary and sexual dysfunction $[11,12]$. Two previous meta-analyses performed approximately 10 years ago indicated LLND had no advantage in controlling recurrence or improving survival and appeared to be associated with increased urinary and sexual dysfunction [13, 14]. However, neither of these two meta-analyses explicitly restricted tumor anatomical location and clinical stage, leading to upper rectal cancers and early-stage rectal cancers were included in their studies. Actually, the application of LLND in upper-third or early-stage rectal carcinoma has practically been abandoned since 2000, and LLND was primarily performed for locally advanced lower rectal cancer at present [4]. In addition, nCRT is currently the primary treatment regimen for locally advanced rectal cancer, and neither of these two meta-analyses separately assessed the effects of LLND on patients who have received preoperative nCRT.

Studies, including large RCTs and well-designed cohorts, performed earlier to clarify the significance of LLND in stage II/III lower rectal cancer, although could not provide clear results $[9,15,16]$. Thus, this metaanalysis is an attempt to integrate the outcomes of previous studies. It assesses the efficacy and safety of LLND in locally advanced lower rectal cancer with or without nCRT which is remained controversial. The protocol for this meta-analysis was registered prospectively with PROSPERO (CRD42020135575).

\section{Methods}

\section{Literature search}

A systematic search of all peer-reviewed literature was performed in electronic databases, including MEDLINE (via PubMed), Embase, Ovid, and the Cochrane Library up to 22 December 2019. The literature of the Google Scholar database was also reviewed. The following $\mathrm{MeSH}$ search headings and their synonyms were used: "total mesorectal excision," "lateral lymph node dissection," "extended lymphadenectomy," "lateral pelvic wall lymph-node dissection," "rectal neoplasms," "rectal cancer," "comparative study," and "treatment outcome." The related-articles were used to broaden the search. The reference lists of relevant studies and systematic reviews were screened manually. A full-text review was performed after a screening of the title and abstract. The data were extracted based on criteria framed.

\section{Selection criteria}

All comparative studies evaluating the efficiency or safety of TME combined with LLND versus TME alone in the treatment of stage II/III lower rectal cancer were included. Studies with the following inclusion criteria were eligible: (1) patients with locally resectable clinical stage II/III rectal cancer without evidence of distal metastasis and tumor location within $8 \mathrm{~cm}$ from the anal verge, or the major part of tumor located at or below the peritoneal reflection; (2) Patients between the two groups with similar clinical characteristics and therapeutic protocols. The following exclusion criteria were used: (1) tumor lesions located in the upper third of the rectum, or the major part of tumor located above the 
peritoneal reflection; (2) patients with significantly different clinical characteristics between the two groups; (3) patients with distant metastasis at the time of treatment or other malignant diseases or fixed tumors; and (4) animal studies, letters, comments, and editorials. In cases of the considerable overlap in subjects between studies published on a single clinical trial, the most recent or most informative study was included, and the results were used complementary.

\section{Data extraction}

Two reviewers independently performed data extraction and study quality assessment. Consistent extraction data, between reviewers were used directly for the final analysis. Disagreements between reviewers were discussed and resolved via consensus. The primary endpoints were 5-year overall survival (OS) and disease-free survival (DFS). Secondary endpoints including total recurrence, local recurrence, lateral recurrence, distant recurrence, operation time, intraoperative blood loss, postoperative complications and mortality, urinary dysfunction, and sexual dysfunction.

\section{Study quality assessment}

The Newcastle-Ottawa scale criteria recommended by the Cochrane Library for including trials were used to evaluate the quality of the cohort studies. The quality of RCTs was measured by using the Cochrane Collaboration's risk for a bias assessment tool. Two reviewers assessed the quality of the studies. Where discrepancies arose, papers were re-examined, and the consensus was reached via discussion.

\section{Statistical analysis}

The meta-analysis is based on Cochrane Collaboration and the Quality of Reporting of Meta-analyses (QUORUM) guidelines [17, 18]. Hazard ratios (HRs) and the respective $95 \%$ confidence intervals (CIs) were assessed as effective measures for time-to-event data (5year OS and DFS). In the absence of HR information, we used the estimation of data from other given information (e.g., Kaplan-Meier plots) [19, 20]. Risk ratio (RR) was used as the summary statistic for statistical analyses of dichotomous variables, and weighted mean difference (WMD) was used to analyze continuous variables. Pvalues for the overall effects were calculated based on a two-sided $Z$-test for independent samples for effective measures on a $\log$ scale. A $P$ value $<0.05$ was considered statistically significant. Meta-analytic results were graphically displayed in Forest plots. Heterogeneity was tested using chi-squared analyses and defined as present in cases of a $P$ value $<0.10 . I^{2}>40 \%$ was considered statistically significant heterogeneity, and the random-effects model was used to calculate overall effect estimates after examining the causes of heterogeneity. Otherwise, the fixed-effects model was used. Subgroup analysis was performed based on whether preoperative nCRT was undertaken. Review Manager version 5.3 was used for the meta-analysis (Copenhagen, the Nordic Cochrane Centre) [21].

\section{Results}

\section{Study selection}

A total of 1564 citations were identified using the predefined search strategy (Fig. 1). After screening the titles and abstracts, 1499 of the studies were excluded due to lack of relevance. Sixty-five articles were further evaluated for eligibility. Among these publications, 54 studies were excluded due to the following reasons: 32 studies did not meet selection criteria; 2 studies were meta-analyses; 14 studies were reviews; 3 studies data were not extractable; 3 studies with overlapping data. Four studies based on one same randomized trial were included because they reported different outcomes. Full manuscripts were available for 11 studies, and the results of one RCT were available as a conference proceeding presented on the 2017 ECCO European Cancer Congress [15]. Finally, twelve studies published from 2001 to 2019 and involving a total of 4458 patients (1952 in the TME + LLND group and 2506 in the TME alone group) fulfilled the selection criteria were included in the current meta-analysis. The flow diagram is shown in Fig. 1.

\section{Characteristics of the included studies}

Six studies were RCTs, and the remaining six studies were non-RCTs. According to the Cochrane bias assessment, all of the RCTs mentioned "randomization," but only four studies (based on the same research) reported as an adequate randomized sequence and mentioned that the allocation procedure was not masked to investigators or patients. Another two RCTs failed to report the randomization procedure or mentioned whether blinding was adopted (please refer. Additional file 1 and Additional file 2). The six non-RCTs were all cohort studies, including five retrospective studies and one prospective study with prospectively collected data. The quality of the nonRCTs was evaluated using the Newcastle-Ottawa criteria. As shown in Table 1, the total number of stars of the six non-RCTs was not less than seven for each study. The basic information about the eligible studies is listed in Table 2. Study outcomes are shown in Table 3.

\section{Primary endpoints: 5-year OS and DFS}

Four studies, with a total of 2189 patients, were pooled into the analysis of 5-year OS [9-12]. The results demonstrated no significant difference in 5-year OS between the LLND group and TME alone group (HR 0.93, 95\% CI $0.71-1.22, P=0.62)$ with moderate heterogeneity $\left(I^{2}=\right.$ 


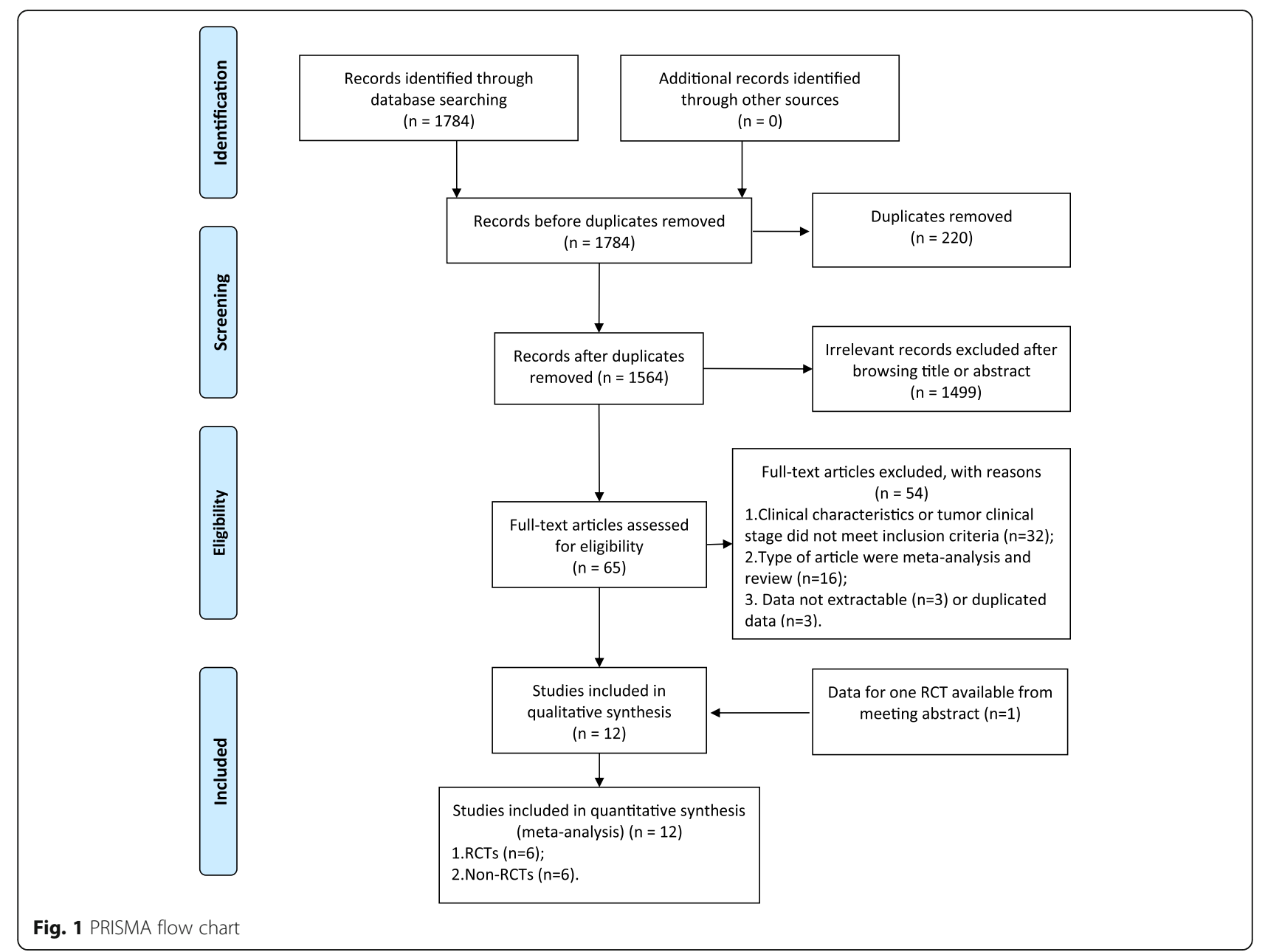

$50 \%, \underline{P}=0.11)$. Subgroup analysis showed no significant difference in 5-year OS between the two groups no matter nRCT used or not (HR $=1.41,95 \%$ CI $0.56-3.55, P=0.47$ vs $\mathrm{HR}=0.90,95 \% \mathrm{CI} 0.68-1.20, P=0.42$ ). The details are shown in Fig. 2a.

Five studies of 1552 patients, were pooled into the analysis of 5-year DFS [2, 9, 11, 12, 22]. The results have no significant difference in 5-year DFS between the two groups (HR 0.99 , $95 \% \mathrm{CI} 0.74-1.34, P=0.96)$ with moderate heterogeneity $\left(I^{2}=50 \%, P=0.08\right)$ between-studies. Subgroup analysis showed no significant difference in 5-year DFS between these two groups regardless of the application of nCRT $(\mathrm{HR}=0.71$, 95\% CI $0.40-1.25, P=0.23$ vs $\mathrm{HR}=1.08,95 \%$ CI $0.75-1.55$, $P=0.69$ ). The details are shown in Fig. $2 \mathrm{~b}$.

\section{Secondary endpoints: total, local, lateral, and distant recurrence, operation time, intraoperative blood loss, postoperative complications, perioperative mortality, sexual, and urinary dysfunction}

Four studies with a total of 1107 patients were eligible for the analysis of 5-year total recurrence [2, 9, 11, 22]. No significant difference in total recurrence was found between the two LLND and TME groups (RR 0.98, 95\% CI $0.81-1.18, P=0.83)$ with no heterogeneity $\left(I^{2}=0 \%\right.$, $P=0.67)$ between-studies. Subgroup analysis showed no significant difference in 5-year DFS between the two groups regardless of the application of $\mathrm{nCRT}(\mathrm{RR}=1.46$, 95\% CI $0.76-2.81, P=0.25$ vs $\mathrm{RR}=0.94$, 95\% CI $0.77-$ 1.14, $P=0.53)$. The details are shown in Fig. 3a.

Seven studies with a total of 3220 patients were pooled into the analysis of 5-year local recurrence $[2,6,9,11$, 12, 16, 22]. The results indicated the LLND group had significantly lower 5 -year local recurrence than the TME alone group (RR $0.71,95 \%$ CI $0.56-0.89, P=0.003$ ) with low between-study heterogeneity $\left(I^{2}=24 \%, P=0.24\right)$. Subgroup analysis found the LLND group had a significantly lower incidence of local recurrence than the TME alone group when preoperative nCRT was not performed (RR 0.71, 95\% CI 0.56-0.89, $P=0.004$ ). However, the difference was not significant once nCRT was introduced (RR 0.70, 95\% CI 0.32-1.51, $P=0.36$ ). The details are shown in Fig. 3b.

Data on 5-year lateral recurrences were extracted from 3 studies with 2369 patients $[6,9,16]$. The results 


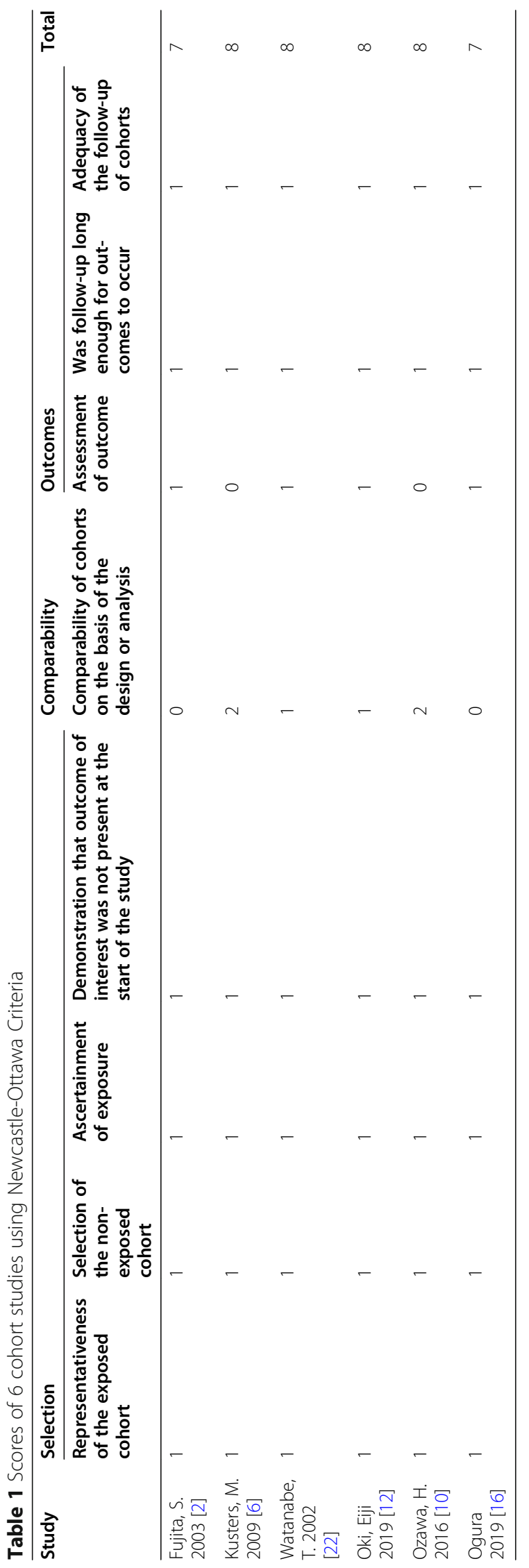




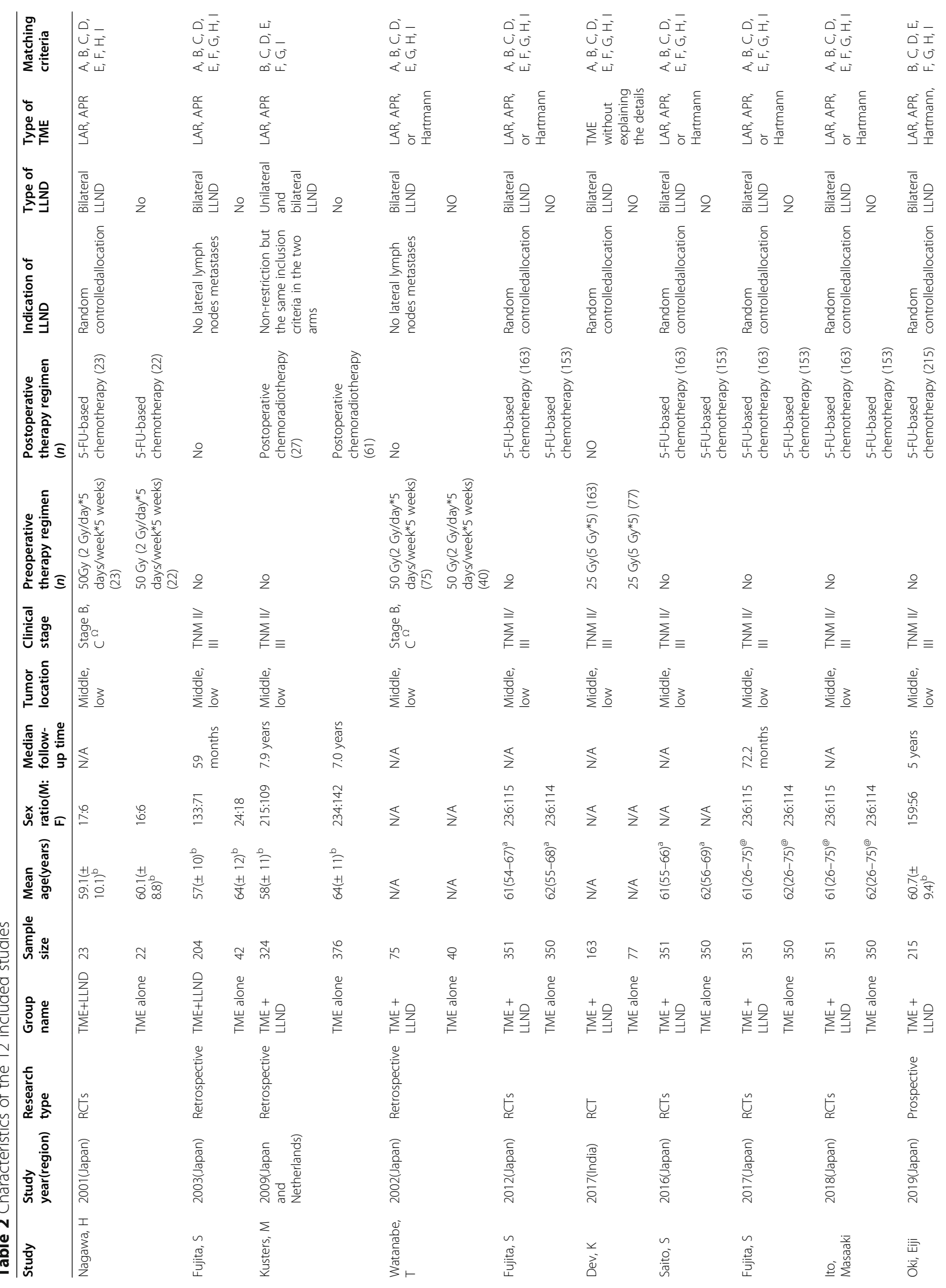




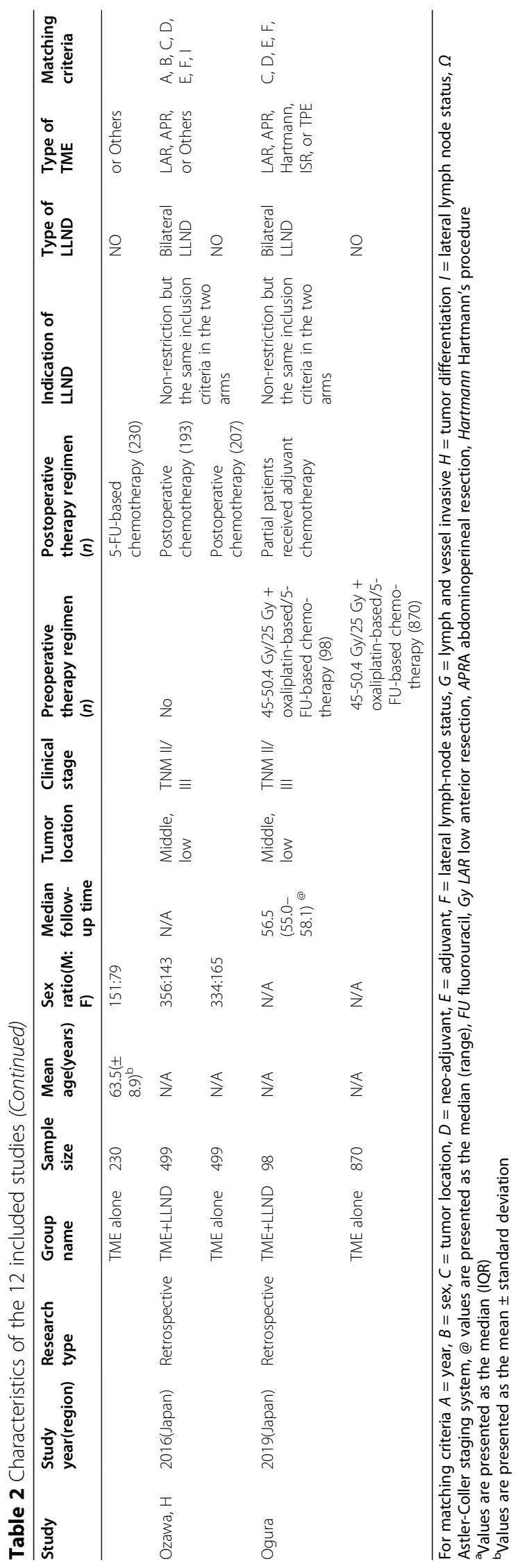


Table 3 Results of meta-analysis comparing TME + LLND versus TME alone

\begin{tabular}{|c|c|c|c|c|c|c|c|c|c|c|}
\hline & \multirow{2}{*}{$\begin{array}{l}\text { Number of } \\
\text { studies }\end{array}$} & \multirow{2}{*}{$\begin{array}{l}\text { TME + LLND } \\
\text { patients }\end{array}$} & \multirow{2}{*}{$\begin{array}{l}\text { TME } \\
\text { patients }\end{array}$} & \multirow{2}{*}{$\begin{array}{l}\text { Total } \\
\text { patients }\end{array}$} & \multirow{2}{*}{$\begin{array}{l}\text { HR/RR/WMD (95\% } \\
\mathrm{Cl)}\end{array}$} & \multirow{2}{*}{$\begin{array}{l}P \\
\text { value }\end{array}$} & \multicolumn{4}{|c|}{ Study heterogeneity } \\
\hline & & & & & & & $\overline{x^{2}}$ & df & $P^{2}$ & $\begin{array}{l}P \\
\text { value }\end{array}$ \\
\hline \multicolumn{11}{|l|}{ Survival } \\
\hline 5-year survival & 4 & 1088 & 1101 & 2189 & $0.93^{\mathrm{a}}(0.71-1.22)$ & 0.62 & 6 & 3 & $50 \%$ & 0.11 \\
\hline $\begin{array}{l}\text { 5-year disease-free } \\
\text { survival }\end{array}$ & 5 & 868 & 684 & 1552 & $0.99^{\mathrm{a}}(0.74-1.34)$ & 0.96 & 9.93 & 5 & $50 \%$ & 0.08 \\
\hline \multicolumn{11}{|l|}{ Recurrence } \\
\hline Total recurrence & 4 & 653 & 454 & 1107 & $0.98(0.81-1.18)$ & 0.83 & 2.37 & 4 & $0 \%$ & 0.67 \\
\hline Local recurrence & 7 & 1290 & 1930 & 3220 & $0.71(0.56-0.89)$ & 0.003 & 9.22 & 7 & $24 \%$ & 0.24 \\
\hline Lateral recurrence & 3 & 773 & 1596 & 2369 & $0.49(0.18-1.28)$ & 0.14 & 5.87 & 2 & $66 \%$ & 0.05 \\
\hline Distant recurrence & 5 & 615 & 1204 & 1819 & $0.95(0.68-1.34)$ & 0.78 & 8.84 & 5 & $43 \%$ & 0.12 \\
\hline \multicolumn{11}{|l|}{ Peri-operative outcomes } \\
\hline $\begin{array}{l}\text { Length of operation } \\
\text { (min) }\end{array}$ & 4 & 716 & 479 & 1195 & $\begin{array}{l}97.03^{b}(75.35- \\
118.72)\end{array}$ & $\begin{array}{l}P< \\
0.001\end{array}$ & 82.14 & 3 & $96 \%$ & $\begin{array}{l}P< \\
0.001\end{array}$ \\
\hline Blood loss (mL) & 4 & 716 & 479 & 1195 & $\begin{array}{l}303.20^{\mathrm{b}}(156.82- \\
449.58)\end{array}$ & $\begin{array}{l}P< \\
0.001\end{array}$ & 201.99 & 3 & $99 \%$ & $\begin{array}{l}P< \\
0.001\end{array}$ \\
\hline $\begin{array}{l}\text { Peri-operative } \\
\text { mortality }\end{array}$ & 2 & 578 & 414 & 992 & $1.52(0.18-12.65)$ & 0.7 & 0.47 & 1 & $0 \%$ & 0.49 \\
\hline $\begin{array}{l}\text { Postoperative } \\
\text { complications }\end{array}$ & 3 & 578 & 414 & 992 & $1.35(1.05-1.74)$ & 0.02 & 0.53 & 2 & $0 \%$ & 0.77 \\
\hline \multicolumn{11}{|l|}{ Functional outcomes } \\
\hline Urinary dysfunction & 2 & 374 & 372 & 746 & $1.44(0.63-3.28)$ & 0.38 & 4.93 & 1 & $80 \%$ & 0.03 \\
\hline Sexual dysfunction & 2 & 108 & 92 & 200 & $1.41(0.87-2.31)$ & 0.17 & 2.23 & 1 & $55 \%$ & 0.13 \\
\hline
\end{tabular}

demonstrated no significant difference in lateral recurrence between the two groups (RR 0.49, 95\% CI 0.18$1.28, P=0.14)$ with moderate heterogeneity $\left(I^{2}=66 \%, P\right.$ $=0.05)$. Subgroup analysis indicated no significant difference in lateral recurrence between the two groups regardless of the introduction of nCRT $(\mathrm{RR}=0.72,95 \% \mathrm{CI}$ $0.27-1.97, P=0.53$ vs $\mathrm{RR}=039,95 \%$ CI $0.08-1.89, P=$ 0.24). The details are shown in Fig. 3c.

Over 5-year distant recurrence was reported in 5 studies that investigated 1819 patients $[2,11,12,16,22]$. The results demonstrated no significant difference in distant recurrence between the two groups (RR 0.95, 95\% CI $0.68-1.34, P=0.78)$ with moderate heterogeneity $\left(I^{2}=\right.$ $43 \%, P=0.12)$. Subgroup analysis revealed no significant difference in distant recurrence between the two groups regardless of the application of $\mathrm{nCRT}(\mathrm{RR}=0.74,95 \%$ CI $0.41-1.33, P=0.32$ vs $\mathrm{RR}=1.14,95 \%$ CI $0.89-1.47$, $P=0.29$ ). The details are shown in Fig. $3 \mathrm{~d}$.

Four studies were included in the meta-analysis that assessed the length of operation in 1195 patients [2, 11, 15, 23]. Results demonstrated a significant difference that favored the TME alone group (WMD $90.73 \mathrm{~min}$,
95\% CI 75.35-118.72, $P<0.001)$ with heterogeneity $\left(I^{2}\right.$ $=96 \%, P<0.001)$. The details are shown in Fig. 4a.

Four studies were included in the meta-analysis to assess intraoperative blood loss in 1195 patients [2, 11, 15, 23]. Results indicated the TME alone group showed significantly lower intraoperative blood loss than the LLND group (WMD $303.20 \mathrm{~mL}, 95 \%$ CI 156.82-449.58, $P<$ $0.001)$ with high heterogeneity $\left(I^{2}=99 \%, P<0.001\right)$. The details are shown in Fig. 4b.

Three studies assessed 992 patients and reported postoperative complications [2, 11, 23]. The LLND group was associated with a higher rate of postoperative complications than the TME alone group $(\mathrm{RR}=1.35,95 \% \mathrm{CI}$ $1.05-1.74, P=0.02)$ with no heterogeneity $\left(I^{2}=0 \%, P=\right.$ 0.77). The details are shown in Fig. 5 a.

Perioperative mortality was reported in three studies that investigated 992 patients [2, 11, 23]. The data extracted from one of the studies were not suitable for meta-analysis because no events were mentioned in either group [11]. Ultimately, two studies, including 947 patients, were pooled into analysis $[2,23]$. The results indicated no significant difference in perioperative 


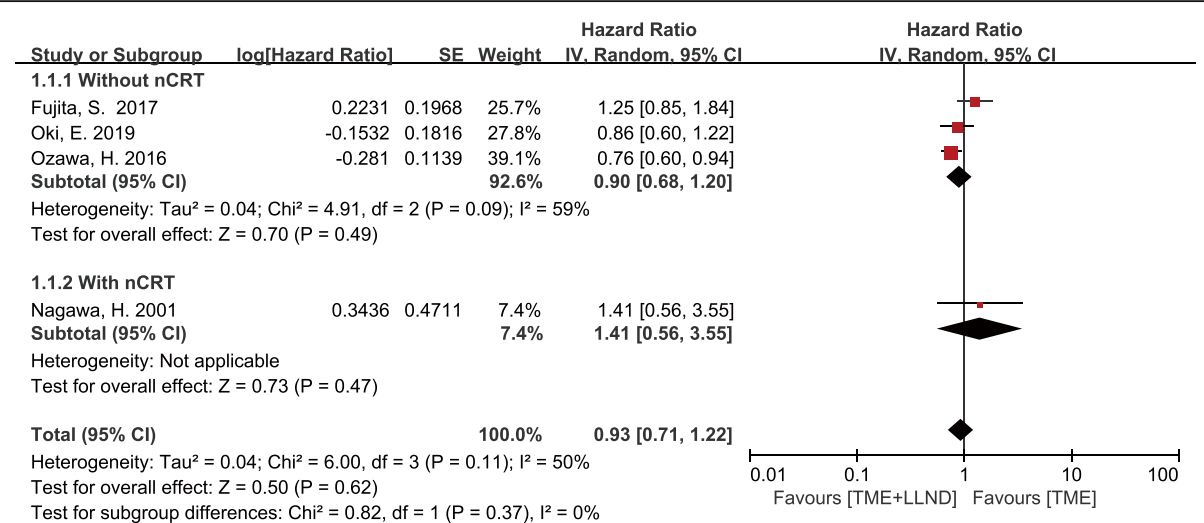

(a)

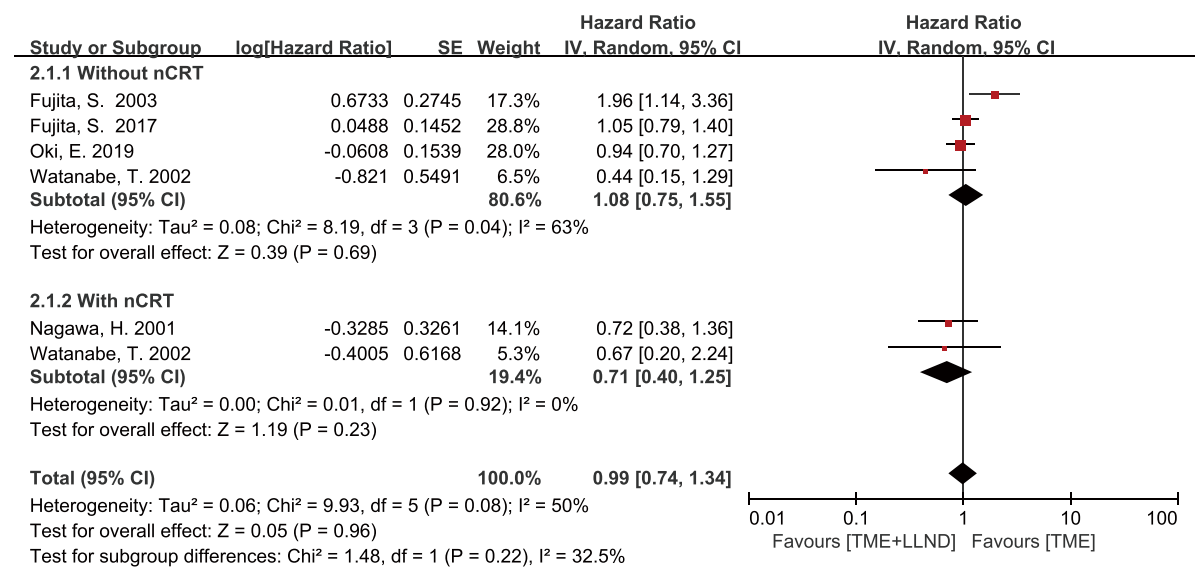

(b)

Fig. 2 Total mesorectal excision and lateral lymph node dissection versus total mesorectal excision alone in 5-year overall survival (a), and 5-year disease-free survival (b); nCRT neoadjuvant chemoradiotherapy

mortality between the two groups ( $\mathrm{RR}=1.52,95 \% \mathrm{CI}$ $0.18-12.65, P=0.70)$ with no heterogeneity $\left(I^{2}=0 \%, P=\right.$ 0.49). The details are shown in Fig. 5b.

Two RCTs studies assessed 200 patients reported sexual dysfunction [11, 24]. Results indicated no significant difference in sexual dysfunction between two groups (pooled RR 1.41, 95\% CI 0.87-2.31, $P=0.17$ ) with moderate heterogeneity $\left(I^{2}=55 \%, P=0.13\right)$. The details are shown in Fig. 5c.

Two RCTs studies of 746 patients assessed and reported urinary dysfunction $[11,25]$. Our results demonstrated no significant difference in urinary dysfunction between the two groups (pooled RR 1.44, 95\% CI 0.63$3.28, P=0.38)$ with high heterogeneity $\left(I^{2}=80 \%, P=\right.$ 0.03). The details are shown in Fig. 5 d.

\section{Discussion}

This meta-analysis is to assess the efficiency and safety of LLND in stage II/III of lower rectal cancer. The study demonstrates LLND reduced the local recurrence significantly without any considerable impact on distant cancer recurrence. Nevertheless, it has no advantage in increasing the rate of survival irrespective of nCRT use.

LLND showed significantly reduced local recurrence in patients who did not receive nCRT. This is neither posed additional risk of postoperative mortality nor increase the risk of sexual and urinary dysfunction. Our results do vary from previous meta-analyses performed by Georgiou et al. and Chen et al. a decade ago [13, 14]. Their studies suggested LLND neither reduced tumor recurrence nor prolonged survival time but significantly affected urinary and sexual function. However, the limited quality of the studies is included in analyses, inherent flaws in their results. For example, the clinical characteristics were significantly different between the two groups, and the LLND group had more advanced tumors, i.e., larger (higher $\mathrm{T}$ stage) [26], node-positive $[26,27]$, and more aggressive pathology [28] compared to the TME alone group. Furthermore, upper rectal cancers and early-stage rectal tumors (T1) were also included in their studies [28-32]. However, the Japanese guidelines have recommended the application of LLND 


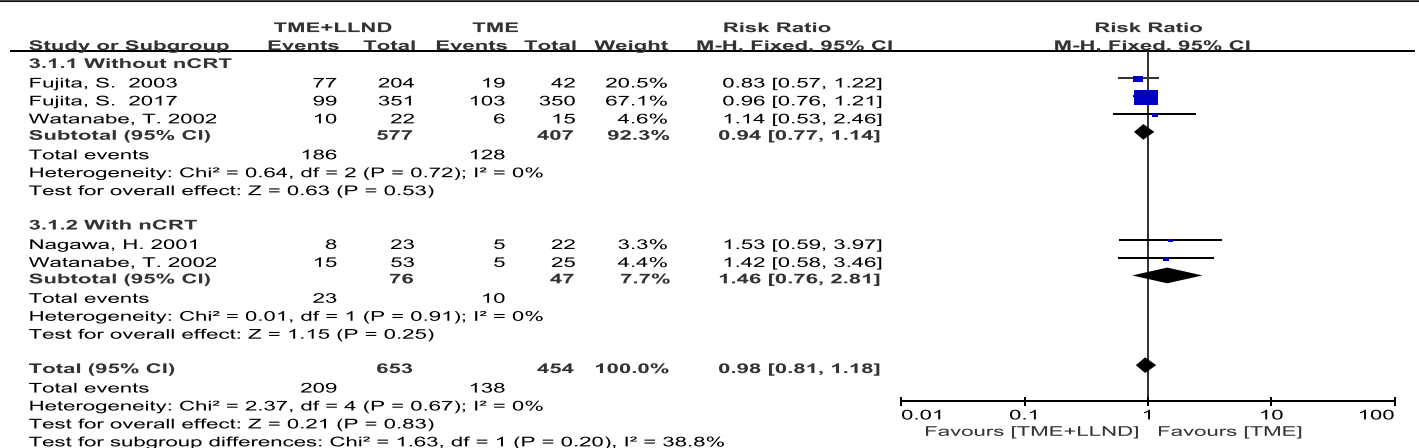

(a)

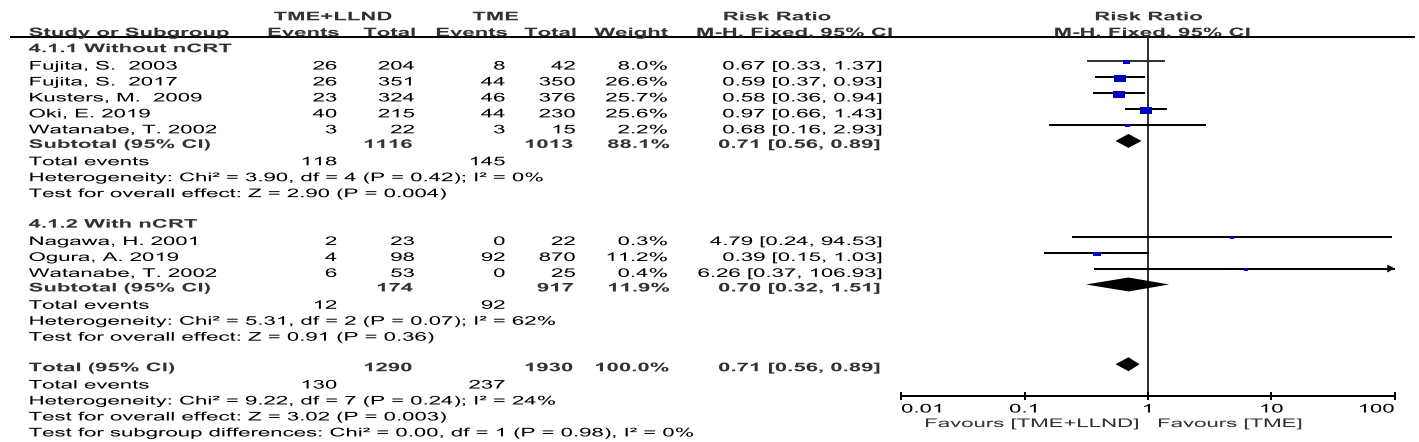

(b)

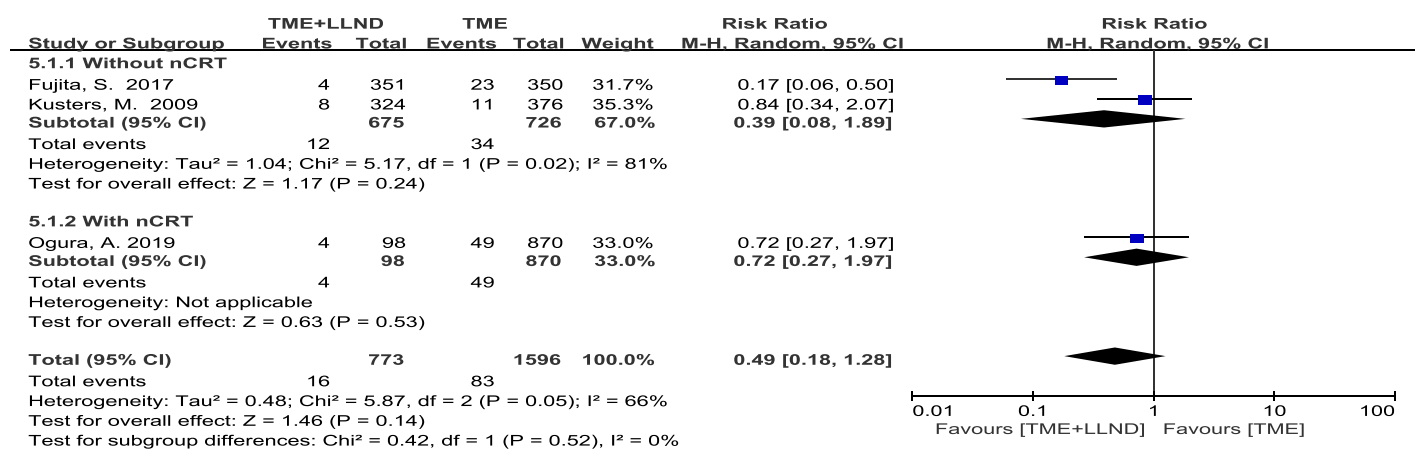

(c)

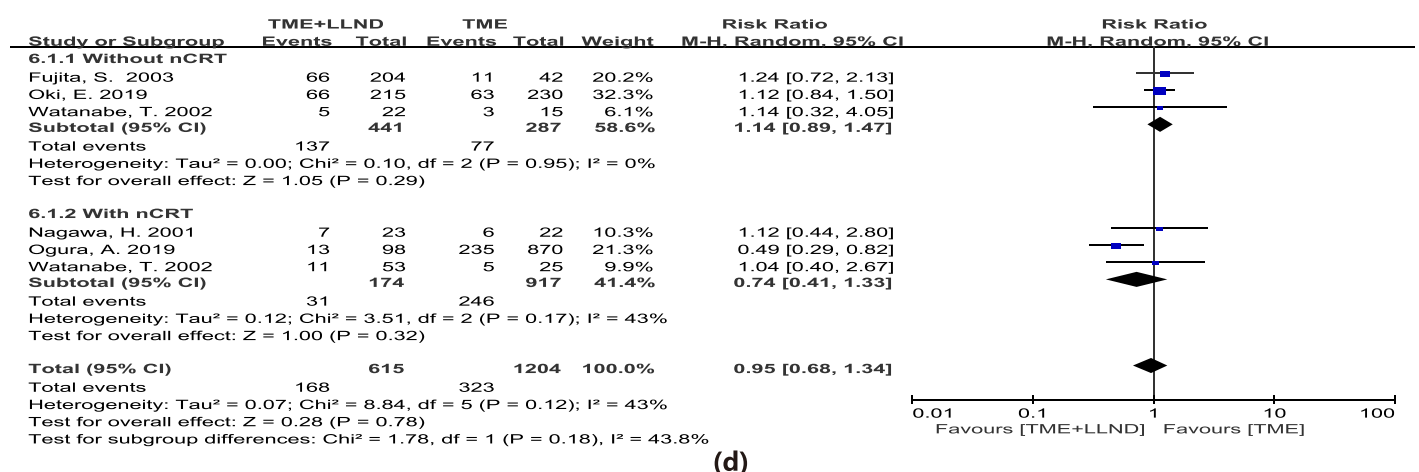

Fig. 3 Total mesorectal excision and lateral lymph node dissection versus total mesorectal excision alone in 5-year total recurrence (a), local recurrence $(\mathbf{b})$, lateral recurrence $(\mathbf{c})$, and distant recurrence $(\mathbf{d})$; nCRT neoadjuvant chemoradiotherapy 


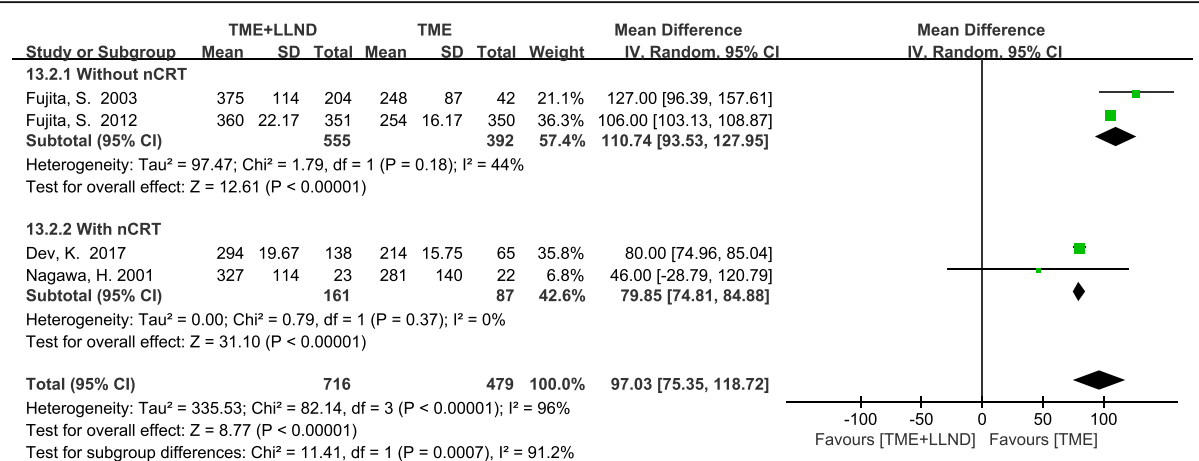

(a)

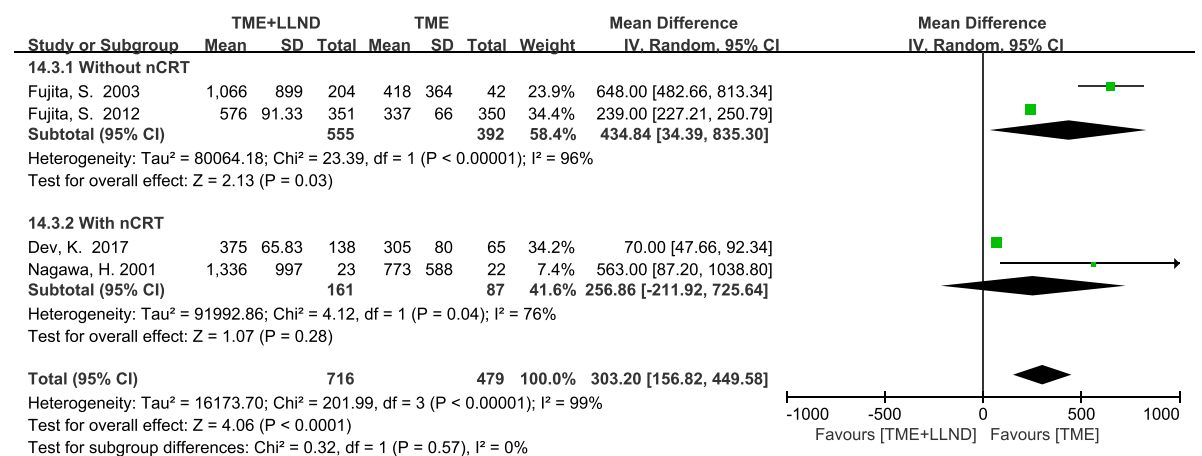

(b)

Fig. 4 Total mesorectal excision and lateral lymph node dissection versus total mesorectal excision alone in operation time (a), and intraoperative blood loss (b); nCRT neoadjuvant chemoradiotherapy

limited to stage II/III of lower rectal cancer regardless of lymphatic node metastasis [4]. Besides this, in the study performed by Chen and colleagues, the time-to-event data were analyzed as dichotomous outcomes instead of the generally recommended method of log HRs and its standard error [14]. Therefore, there were certain limitations in applying their results to guide the application of LLND in clinical practice. Our study included more high-quality trials than the previous two meta-analyses. Therefore, our study provides more powerful and valid results than the previous two meta-analyses.

Our results demonstrated LLND significantly reduced local recurrence of the patients who didn't receive nCRT, but the difference was not significant when nCRT was performed. These results indicated the advantage of LLND in controlling local recurrence might be replaced with nCRT. Caution should be taken when interpreting these results because no subgroup analysis was performed based on the pretreatment size of LLNs. Previous studies indicated patients with positive LLNs have a higher rate of local recurrence. TME followed by nCRT was not sufficient for radical eradication of the metastatic LLNs to avoid local recurrence [33, 34]. Akiyoshi et al. reported $30-40 \%$ of patients with positive LLN developed local recurrence even after $\mathrm{nCRT}$, and it reduced to almost zero when additional LLND was performed [35]. Ogura et al. also noted that $25.6 \%$ of patients with positive LLN developed local recurrence even after receiving $\mathrm{nCRT}$ and radical resection, and reduced to 5.7\% when extra LLND was performed [16]. Therefore, for patients with positive LLNs who undergo nCRT followed by TME alone may not be sufficient, and selective LLND should probably be considered [7, 33]. The value of selective LLND in patients who received nCRT remains controversial. A current phase III Chinese randomized controlled trial (NCT02614157) to demonstrate the safety and efficacy of selective LLND after nCRT in the treatment of advanced lower rectal cancerbearing enlarged LLNs is being performed and may provide more reliable evidence [36].

The pattern of local recurrence can be divided into three categories: central pelvis recurrence, anastomosis recurrence, and lateral recurrence. The current study found LLND reduced the incidence of lateral recurrence, but without significant difference. The reason may be the different local recurrence patterns in the studies. Several studies have shown that the most common site of local recurrence varies among patients of different 


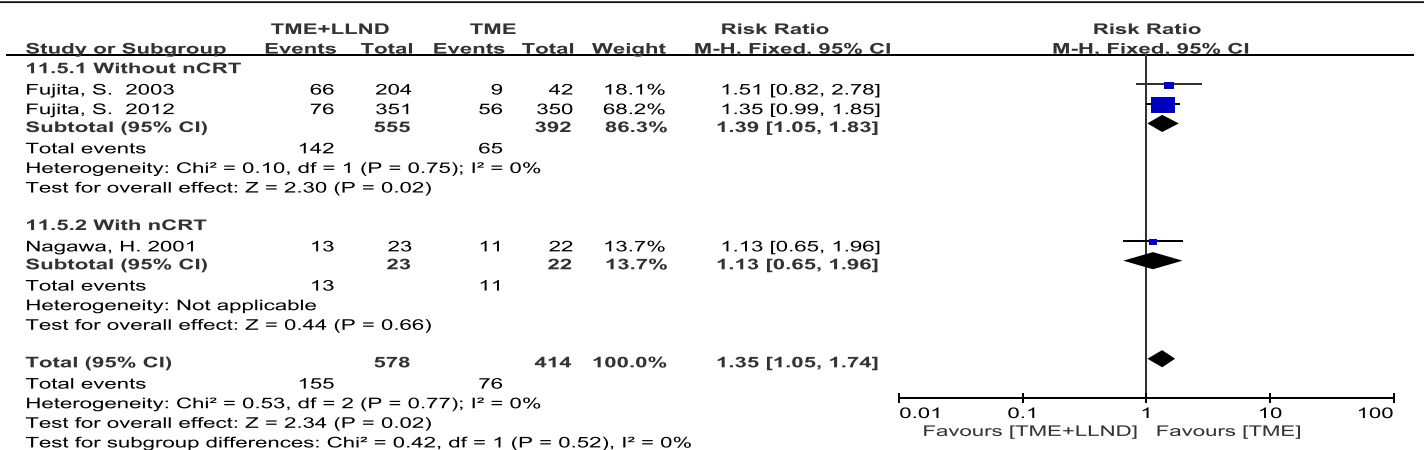

(a)

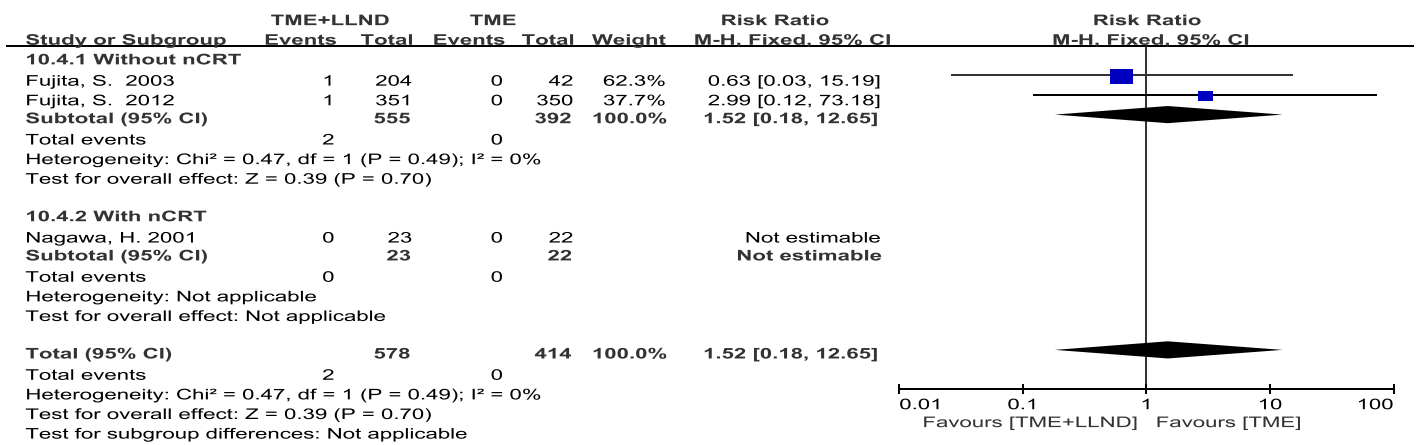

(b)

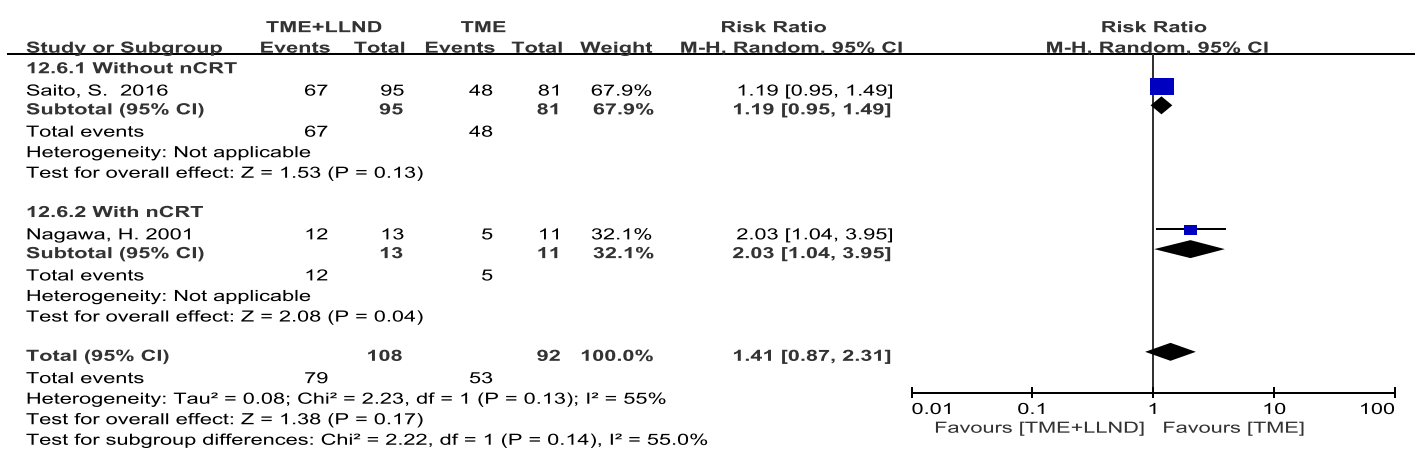

(c)

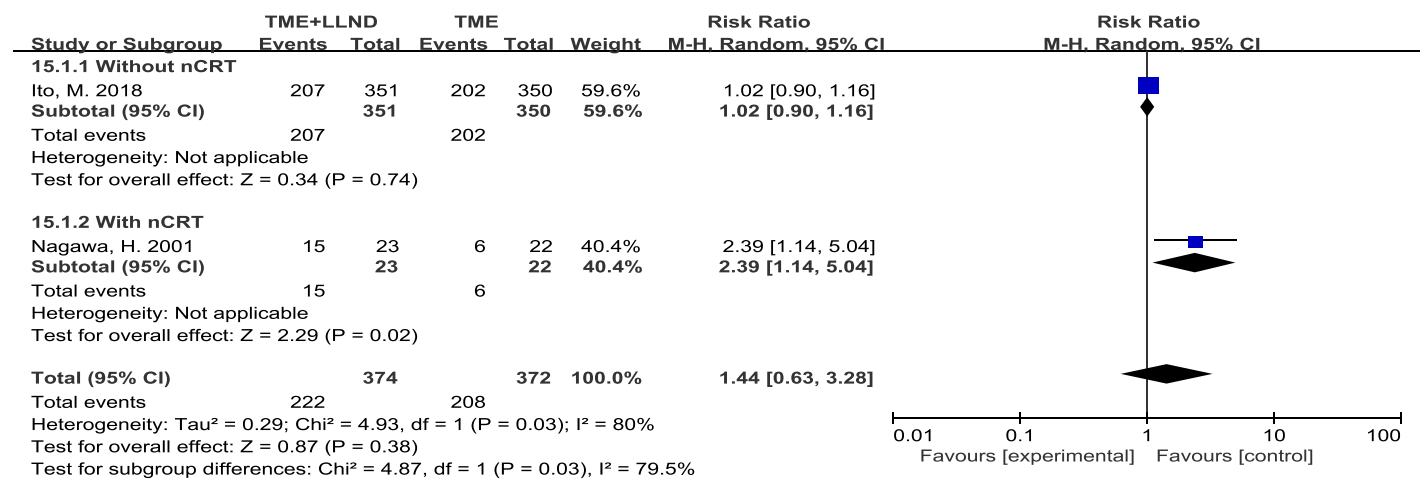

(d)

Fig. 5 Total mesorectal excision and lateral lymph node dissection versus total mesorectal excision alone in postoperative complications (a), perioperative mortality (b), postoperative sexual dysfunction (c), and postoperative urinary dysfunction (d); nCRT neoadjuvant chemoradiotherapy 
geographical regions. A Dutch trial indicated the most common site of recurrence was the central pelvis, and only $24 \%$ of the local recurrence originated from the lateral pelvis in the TME alone group [6]. Further, a study from Sweden also demonstrated lateral recurrence was not a major cause of local recurrence, and only 6\% (2/ 33) of patients with local recurrence exhibited lateral pelvic recurrence [37]. However, a study by Nagasaki et al. from Japan suggested the most common site of local recurrence was the lateral pelvis, and approximately $50 \%$ of the patients with local recurrence developed lateral recurrence [38]. In addition, a study by Kim et al. from Korea also demonstrated approximately $65 \%$ $(42 / 65)$ of patients with local recurrence developed lateral pelvic recurrence even after receiving nCRT and radical dissection [39]. Analogously, Fujita et al. reported a much higher rate of lateral pelvic recurrence $(57 \%)$ in the TME alone group than Kusters and colleagues (24\%) in the current meta-analysis, which may be the reason for high heterogeneity in the study $[6,9]$. Therefore, patients in East Asia tend to have a higher incidence of lateral pelvic recurrence, and LLND may play a more important role in East Asian patients than patients in Europe.

We also found that LLND couldn't improve the overall 5-year survival or DFS of patients with rectal cancer regardless of the application of nCRT. The results indicate LNNs metastases might be a sign of systemic disease with a poor prognosis rather than a regional disease and couldn't be eliminated by surgery only [5]. Previous studies have demonstrated that the 5-year OS of patients with lateral lymph node enlargement is still poor (20$45 \%)$ even though local control has been achieved by the application of LLND [1, 40, 41]. Oki et al. also indicated LLND brings no benefits in improving 5 -year DFS or OS of patients who did not receive nCRT [12]. Besides, the Japanese randomized trial also demonstrated LLND could not prolong the survival time of patients with rectal cancer [9]. The latest tumor node metastasis (TNM) classification by AJCC 8th edition classification LLNs involvement as distant disease, and TME followed by nCRT has been recommended as the standard treatment regimens [42]. However, whether LLND provides additional benefits to patients who have received nCRT remains controversial.

This meta-analysis result did not find any significant differences in 5-year OS and DFS between these groups after receiving $\mathrm{nCRT}$. It is worth noting that these results were obtained without limiting the pretreatment size of LLNs and studies with negative LLNs were also included in our study. While, it has been reported that the pretreatment size of LLNs was significantly associated with survival outcomes, and patients with positive LLNs have significantly worse survival rates [39, 43].
MERCURY study demonstrated patients with enlarged LLNs had significantly lower 5-year DFS than that of the patients with negative LLNs (42\% vs 70.7\%) [43]. Kim et al. also identified LLNs short-axis diameter $\geq 10 \mathrm{~mm}$ was significantly associated with lower 5 -year OS and DFS, even after nCRT and TME [39]. A subgroup analysis based on the pretreatment size of LLNs was planned during the design phase of the present metaanalysis, but no sufficiently detailed information was provided in the included trials to perform this subgroup analysis. Therefore, whether LLND provides additional survival benefits to patients with pretreatment-positive LLNs who received nCRT remained a mystery. A phase III Chinese randomized controlled trial (NCT02614157) may provide strong evidence on it [36].

Our data demonstrated TME followed by LLND required longer operation time and resulted in greater blood loss than TME alone. It is not difficult to understand that LLND combined with TME required more operation time because LLND is a meticulous procedure. Two trials performed around 2000 showed the mean difference in intraoperative blood loss was greater than 500 $\mathrm{mL}$ between the two groups $[2,11]$. However, the recent two RCTs by Fujita et al. and Dev et al. showed the mean differences were just $239 \mathrm{~mL}$ and $70 \mathrm{~mL}$, respectively $[15,23]$. A reasonable explanation may be due to the improvements in surgical techniques, and blood loss may have been minimized compared with the earlier studies.

Our study also found that LLND was associated with more frequent and severe postoperative complications, however, did not increase the risk of postoperative mortality. These results should be interpreted with caution when applied to clinical practice, as all three trials included in the current meta-analysis reported extremely low incidences of postoperative mortality in both groups $[2,11,23]$. Notably, the aggregated data also demonstrated LLND did not bring additional risks to sexual or urinary dysfunction. Therefore, the potential damage to urinary and sexual function cannot be a stumbling block to prevent the application of LLND for the treatment of rectal cancer.

The limitations of the current study should not be neglected as a minimal number of RCTs were included, and four of the RCTs studies reported different outcomes based on the same randomized trial. Further, the results of another study were extracted from conference proceedings [15]. However, all of the included studies were of high quality (achieving more than seven stars) according to the Newcastle-Ottawa Scale (for nonRCTs) [44] or the Cochrane Collaboration's risk of bias tool (for RCTs) [45]. The follow-up times were different across studies, but the time was sufficient for outcomes to occur, and subjects lost to follow-up were unlikely to 
introduce bias. Despite meeting the inclusion criteria, clinical heterogeneity may present due to the different pretreatment statuses of LLNs between the included studies, which may have introduced bias. The chemoradiotherapy regimens, preoperative waiting time after neoadjuvant therapy, and specific surgical procedures and quality were different across studies, which presents another possibility to introduce bias. Despite these limitations, the current study provides the most comprehensive and up-to-date information on the frequently discussed value of the routine use of LLND in the treatment of stage II/III lower rectal cancer.

\section{Conclusion}

This study demonstrates the advantage of LLND in locally advanced lower rectal cancer without using nCRT, even though it couldn't make much difference in OS or DFS in 5 years. However, risk of LLND is distressing when lateral lymph node's metastasis already occurred, and concern should be made on the longer operation time, greater blood loss, and other complications. Besides this, the well-controlled large numbers of RCT are needed to demonstrate whether selective LLND provides additional benefits over nCRT with LLND.

\section{Supplementary Information}

The online version contains supplementary material available at https://doi. org/10.1186/s12957-020-02078-1.

Additional file 1. Risk of bias graph of RCTs. Review authors' judgments about each risk of bias item presented as percentages across all included studies.

Additional file 2. Risk of bias summary of RCTs. Review authors' judgments about each risk of bias item for each included study.

\section{Abbreviations}

TME: Total mesorectal excision; LLNs: Lateral pelvic lymph nodes; LLND: Lateral lymph node dissection; nCRT: Neoadjuvant Chemoradiotherapy; HR: Hazard ratio; RR: Relative risk; WMD: Weighted Mean Difference; OS: Overall survival; DFS: Disease-free survival; RCT: Randomised controlled trial; $\mathrm{Cl}$ : Confidence interval

\section{Acknowledgements}

Not applicable.

\section{Authors' contributions}

$X G, C W$, and $Y Y Y$ made substantial contributions to conception and design, acquisition, analysis, and the interpretation of data. $X G, C W, Y Y Y, D S$, and $L Y$ participated in drafting the article. $X G, L Y$, and $Z G Z$ participated in revising it critically for important intellectual content. All of the authors gave final approval of the version to be published.

\section{Funding}

This research did not receive any specific grant from funding agencies in the public, commercial, or non-profit sectors.
Ethics approval and consent to participate

All analyses were based on previously published studies. Therefore, no ethical approval or patient consent was required.

\section{Consent for publication}

Not applicable.

\section{Competing interests}

There are no conflicts of interest of any authors in relation to the submission of this manuscript.

\section{Author details}

${ }^{1}$ Institute of Digestive Surgery, Sichuan University, Chengdu, Sichuan, China. ${ }^{2}$ Department of Gastrointestinal Surgery, West China Hospital, West China School of Medicine, Sichuan University, Chengdu, Sichuan, China.

Received: 11 July 2020 Accepted: 5 November 2020

Published online: 23 November 2020

\section{References}

1. Sugihara K, Kobayashi H, Kato T, et al. Indication and benefit of pelvic sidewall dissection for rectal cancer. Dis Colon Rectum. 2006;49(11):1663-72.

2. Fujita S, Yamamoto S, Akasu T, Moriya Y. Lateral pelvic lymph node dissection for advanced lower rectal cancer. Br J Surg. 2003;90(12):1580-5.

3. Takahashi T, Ueno M, Azekura K, Ohta H. Lateral node dissection and total mesorectal excision for rectal cancer. Dis Colon Rectum. 2000;43(10 Suppl): S59-68.

4. Watanabe T, Muro K, Ajioka Y, et al. Japanese Society for Cancer of the Colon and Rectum (JSCCR) guidelines 2016 for the treatment of colorectal cancer. Int J Clin Oncol. 2018;23(1):1-34.

5. Bosset JF, Collette L, Calais G, et al. Chemotherapy with preoperative radiotherapy in rectal cancer. N Engl J Med. 2006;355(11):1114-23.

6. Kusters M, Beets $G L$, van de Velde CJ, et al. A comparison between the treatment of low rectal cancer in Japan and the Netherlands, focusing on the patterns of local recurrence. Ann Surg. 2009;249(2):229-35.

7. Akiyoshi T, Ueno M, Matsueda $K$, et al. Selective lateral pelvic lymph node dissection in patients with advanced low rectal cancer treated with preoperative chemoradiotherapy based on pretreatment imaging. Ann Surg Oncol. 2014;21(1):189-96.

8. Ishihara S, Kawai K, Tanaka T, et al. Oncological outcomes of lateral pelvic lymph node metastasis in rectal cancer treated with preoperative chemoradiotherapy. Dis Colon Rectum. 2017;60(5):469-76.

9. Fujita S, Mizusawa J, Kanemitsu Y, et al. Mesorectal Excision With or Without Lateral Lymph Node Dissection for Clinical Stage II/II Lower Rectal Cancer (JCOG0212): A multicenter, randomized controlled. Noninferiority Trial. Ann Surg. 2017;266(2):201-7.

10. Ozawa H, Kotake K, Hosaka M, Hirata A, Sugihara K. Impact of lateral pelvic lymph node dissection on the survival of patients with T3 and T4 low rectal cancer. World J Surg. 2016;40(6):1492-9.

11. Nagawa H, Muto T, Sunouchi K, et al. Randomized, controlled trial of lateral node dissection vs. nerve-preserving resection in patients with rectal cancer after preoperative radiotherapy. Dis Colon Rectum. 2001;44(9):1274-80.

12. Oki E, Shimokawa M, Ando K, et al. Effect of lateral lymph node dissection for mid and low rectal cancer: An ad-hoc analysis of the ACTS-RC (JFMC35C1) randomized clinical trial. Surgery. 2019;165(3):586-92.

13. Georgiou P, Tan E, Gouvas N, et al. Extended lymphadenectomy versus conventional surgery for rectal cancer: a meta-analysis. Lancet Oncol. 2009; 10(11):1053-62.

14. Cheng H, Deng Z, Wang ZJ, Zhang W, Su JT. Lateral lymph node dissection with radical surgery versus single radical surgery for rectal cancer: a metaanalysis. Asian Pac J Cancer Prev. 2011;12(10):2517-21.

15. Dev K, Gurawalia J, Krishnamurthy S, Kumar VK, Ramachandra C. Role of lateral lymph node dissection in improving survival in low rectal cancer. A single institute, prospective study. Eur J Cancer. 2017;72(Supplement 1):S65S.

16. Ogura A, Konishi T, Cunningham C, et al. Neoadjuvant (chemo)radiotherapy with total mesorectal excision only is not sufficient to prevent lateral local recurrence in enlarged nodes: results of the multicenter lateral node study of patients with low cT3/4 Rectal Cancer. J Clin Oncol. 2019;37(1):33-43.

17. Clarke M, Horton R. Bringing it all together: Lancet-Cochrane collaborate on systematic reviews. Lancet. 2001;357(9270):1728. 
18. Stroup DF, Berlin JA, Morton SC, et al. Meta-analysis of observational studies in epidemiology: a proposal for reporting. Meta-analysis Of Observational Studies in Epidemiology (MOOSE) group. JAMA. 2000;283(15):2008-12.

19. Tierney JF, Stewart LA, Ghersi D, Burdett S, Sydes MR. Practical methods for incorporating summary time-to-event data into meta-analysis. Trials. 2007;8: 16.

20. Parmar MK, Torri V, Stewart L. Extracting summary statistics to perform meta-analyses of the published literature for survival endpoints. Stat Med. 1998;17(24):2815-34

21. Review Manager (RevMan) [Computer program]. Version 5.3. Copenhagen. The Nordic Cochrane Centre, The Cochrane Collaboration; 2014.

22. Watanabe T, Tsurita G, Muto T, et al. Extended lymphadenectomy and preoperative radiotherapy for lower rectal cancers. Surgery. 2002;132(1):2733.

23. Fujita S, Akasu T, Mizusawa J, et al. Postoperative morbidity and mortality after mesorectal excision with and without lateral lymph node dissection for clinical stage II or stage III lower rectal cancer (JCOG0212): results from a multicentre, randomised controlled, non-inferiority trial. Lancet Oncol. 2012; 13(6):616-21.

24. Saito S, Fujita S, Mizusawa J, et al. Male sexual dysfunction after rectal cancer surgery: Results of a randomized trial comparing mesorectal excision with and without lateral lymph node dissection for patients with lower rectal cancer: Japan Clinical Oncology Group Study JCOG0212. Eur J Surg Oncol. 2016;42(12):1851-8.

25. Ito M, Kobayashi A, Fujita S, et al. Urinary dysfunction after rectal cancer surgery: Results from a randomized trial comparing mesorectal excision with and without lateral lymph node dissection for clinical stage II or III lower rectal cancer (Japan Clinical Oncology Group Study, JCOG0212). Eur J Surg Oncol. 2018;44(4):463-8.

26. Matsuoka H, Masaki T, Sugiyama M, Atomi Y. Impact of lateral pelvic lymph node dissection on evacuatory and urinary functions following low anterior resection for advanced rectal carcinoma. Langenbecks Arch Surg. 2005; 390(6):517-22.

27. Suzuki K, Muto T, Sawada T. Prevention of local recurrence by extended lymphadenectomy for rectal cancer. Surg Today. 1995;25(9):795-801.

28. Kobayashi $\mathrm{H}$, Mochizuki $\mathrm{H}$, Kato $\mathrm{T}$, et al. Outcomes of surgery alone for lower rectal cancer with and without pelvic sidewall dissection. Dis Colon Rectum. 2009:52(4):567-76.

29. Hasdemir O, Col C, Yalcin E, Tunc G, Bilgen K, Kucukpinar T. Local recurrence and survival rates after extended systematic lymph-node dissection for surgical treatment of rectal cancer. Hepatogastroenterology. 2005;52(62): 455-9.

30. Koyama Y, Moriya Y, Hojo K. Effects of extended systematic lymphadenectomy for adenocarcinoma of the rectum--significant improvement of survival rate and decrease of local recurrence. Jpn J Clin Oncol. 1984;14(4):623-32.

31. Col C, Hasdemir O, Yalcin E, Yandakci K, Tunc G, Kucukpinar T. Sexual dysfunction after curative radical resection of rectal cancer in men: the role of extended systematic lymph-node dissection. Med Sci Monit. 2006;12(2): CR70-4.

32. Kyo K, Sameshima S, Takahashi M, Furugori T, Sawada T. Impact of autonomic nerve preservation and lateral node dissection on male urogenital function after total mesorectal excision for lower rectal cancer. World J Surg. 2006;30(6):1014-9.

33. Kim TH, Jeong SY, Choi DH, et al. Lateral lymph node metastasis is a major cause of locoregional recurrence in rectal cancer treated with preoperative chemoradiotherapy and curative resection. Ann Surg Oncol. 2008;15(3):729-37.

34. Kim DJ, Chung JJ, Yu JS, Cho ES, Kim JH. Evaluation of lateral pelvic nodes in patients with advanced rectal cancer. AJR Am J Roentgenol. 2014;202(6): 1245-55.

35. Akiyoshi T, Matsueda K, Hiratsuka M, et al. Indications for Lateral Pelvic Lymph Node Dissection Based on Magnetic Resonance Imaging Before and After Preoperative Chemoradiotherapy in Patients with Advanced LowRectal Cancer. Ann Surg Oncol. 2015;22(Suppl 3):S614-20.

36. Wei $M$, Wu $Q$, Fan $C$, et al. Lateral pelvic lymph node dissection after neoadjuvant chemo-radiation for preoperative enlarged lateral nodes in advanced low rectal cancer: study protocol for a randomized controlled trial. Trials. 2016;17(1):561.

37. Syk E, Torkzad MR, Blomqvist L, Ljungqvist O, Glimelius B. Radiological findings do not support lateral residual tumour as a major cause of local recurrence of rectal cancer. Br J Surg. 2006;93(1):113-9.
38. Nagasaki T, Akiyoshi T, Fujimoto Y, et al. Preoperative chemoradiotherapy might improve the prognosis of patients with locally advanced low rectal cancer and lateral pelvic lymph node metastases. World J Surg. 2017:41(3): 876-83.

39. Kim MJ, Kim TH, Kim DY, et al. Can chemoradiation allow for omission of lateral pelvic node dissection for locally advanced rectal cancer? J Surg Oncol. 2015;111(4):459-64.

40. Sato H, Maeda K, Maruta M, Masumori K, Koide Y. Who can get the beneficial effect from lateral lymph node dissection for Dukes $C$ rectal carcinoma below the peritoneal reflection? Dis Colon Rectum. 2006;49(10 Suppl):S3-12.

41. Ueno $H$, Mochizuki $H$, Hashiguchi $Y$, et al. Potential prognostic benefit of lateral pelvic node dissection for rectal cancer located below the peritoneal reflection. Ann Surg. 2007;245(1):80-7.

42. Weiser MR. AJCC 8th Edition: Colorectal Cancer. Ann Surg Oncol. 2018;25(6): 1454-5.

43. Group MS, Shihab OC, Taylor F, et al. Relevance of magnetic resonance imaging-detected pelvic sidewall lymph node involvement in rectal cancer. Br J Surg. 2011;98(12):1798-804.

44. Stang A. Critical evaluation of the Newcastle-Ottawa scale for the assessment of the quality of nonrandomized studies in meta-analyses. Eur J Epidemiol. 2010;25(9):603-5.

45. Higgins JP, Altman DG, Gøtzsche PC, et al. The cochrane collaboration's tool for assessing risk of bias in randomised trials. BMJ. 2011;343:d5928.

\section{Publisher's Note}

Springer Nature remains neutral with regard to jurisdictional claims in published maps and institutional affiliations.
Ready to submit your research? Choose BMC and benefit from:

- fast, convenient online submission

- thorough peer review by experienced researchers in your field

- rapid publication on acceptance

- support for research data, including large and complex data types

- gold Open Access which fosters wider collaboration and increased citations

- maximum visibility for your research: over $100 \mathrm{M}$ website views per year

At BMC, research is always in progress.

Learn more biomedcentral.com/submissions 